\title{
Large iatrogenic sigmoid colon perforation treated with endoloop-assisted clip closure and over-the-scope clip: a case report
}

A 77-year-old woman was admitted to our Emergency Department for an iatrogenic sigmoid colon perforation that occurred during a diagnostic colonoscopy. The patient complained of moderate abdominal pain without signs of peritonitis. Considering the time since colonoscopy ( $<2$ hours) and the excellent bowel preparation, an attempt was made to treat the perforation endoscopically. Therapeutic colonoscopy was performed under monitored anesthesia care using a singlechannel therapeutic gastroscope (EG3490K; Pentax Medical, Tokyo, Japan) and $\mathrm{CO}_{2}$ insufflation. A $6-\mathrm{cm}$ large fullthickness wall defect at $25 \mathrm{~cm}$ from the anal verge, with active oozing bleeding, was detected (> Fig.1). Bleeding was controlled with 1:10000 adrenaline injection; thereafter an endoloop-assisted clip closure was performed.

We opened a 30-mm endoloop (HX400U-30; Olympus Medical Systems Corp., Tokyo, Japan) around the wall defect; the cable was anchored to the hole margins by launching, one by one, four 13-mm through-the-scope clips (MD-GHR-230-13-135; Zhejiang Chuangxiang Medical Technology Co., Ltd., Hangzhou, China); then the endoloop was hooked, closed, and finally released ( $\mathbf{F i g}$. 2 ). The contrastography showed a 6 -mm residual wall defect that was treated deploying a 12-mm t-type over-the-scope clip (OTSC) (Ovesco, Tübingen, Germany), with no contrast agent extravasation at the end. A computed tomography (CT) scan after the procedure confirmed the absence of contrast extravasation on luminal contrastography. The patient was managed conservatively with bowel rest, intravenous fluids, and broad-spectrum antibiotic therapy. After 5 days, oral feeding was resumed and the patient was discharged. A CT scan with colonic contrast injection performed after 3 weeks showed a complete resolution ( Video 1).

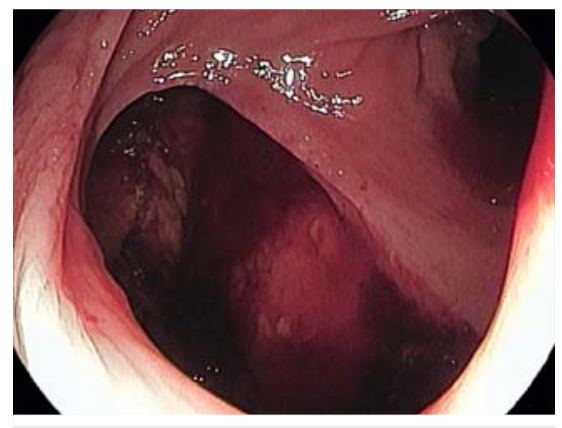

Fig. 1 Full-thickness wall defect of the sigmoid colon.

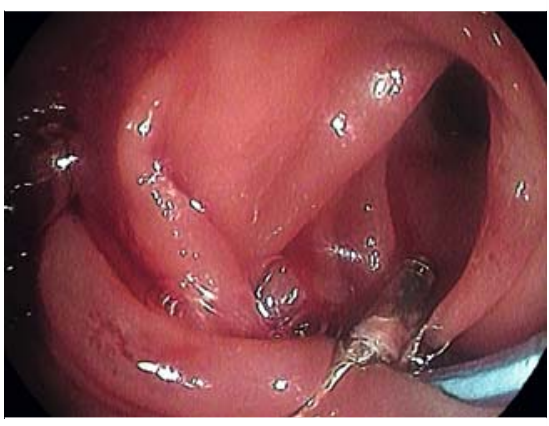

Fig. 2 Wall defect after endoloopassisted clip closure.

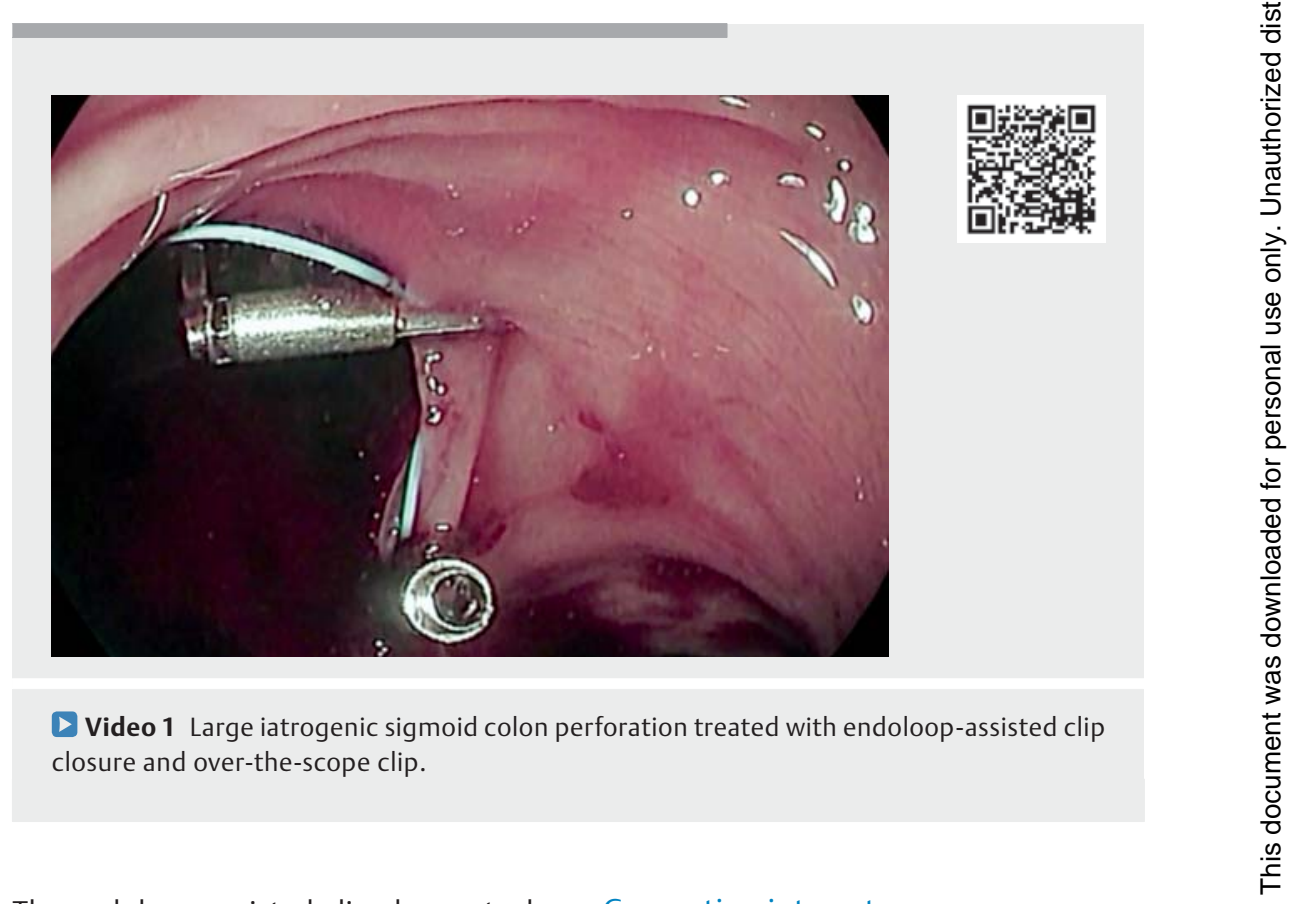

The endoloop-assisted clip closure technique has been reported as a therapeutic solution for iatrogenic perforations. The timing since the perforation is crucial in order to effectively close the leak [1 -5]. In conclusion, in selected cases, the combined endoscopic rescue therapy with endoloop-assisted clip closure and OTSC can be effective in conservative treatment of colonic perforations.

Endoscopy_UCTN_Code_CPL_1AJ_2AH

\section{Competing interests}

The authors declare that they have no conflict of interest. 
The authors

Salvatore Russo ${ }^{1}{ }^{\odot}$, Giuseppe Grande ${ }^{1}$, Raffaele Manta ${ }^{2}$, Santi Mangiafico ${ }^{1}$, Helga Bertani ${ }^{1}$, Flavia Pigò ${ }^{1}$, Rita Conigliaro ${ }^{1}$

1 Azienda Ospedaliero-Universitaria di Modena, Gastroenterology and Digestive Endoscopy Unit

2 Azienda Ospedaliera di Perugia, Gastroenterology and Digestive Endoscopy Unit

\section{Corresponding author}

\section{Salvatore Russo, MD}

Azienda Ospedaliero-Universitaria di Modena, Gastroenterology and Digestive Endoscopy Unit, Via Pietro Giardini 1355, 41126 Modena, Italy russo.salvatore@aou.mo.it

\section{References}

[1] Paspatis GA, Arvanitakis M, Dumonceau JM et al. Diagnosis and management of iatrogenic endoscopic perforations: European Society of Gastrointestinal Endoscopy (ESGE) Position Statement - Update 2020 Endoscopy 2020; 52: 792-810

[2] Ryu JY, Park BK, Kim WS et al. Endoscopic closure of iatrogenic colon perforation using dual-channel endoscope with an endoloop and clips: methods and feasibility data (with videos). Surg Endosc 2019; 33: 1342-1348

[3] Dolezel R, Ryska O, Kollar M et al. A comparison of two endoscopic closures: overthe-scope clip (OTSC) versus KING closure (endoloop + clips) in a randomized longterm experimental study. Surg Endosc 2016; 30: 4910-4916

[4] Katsinelos P, Lazaraki G, Chatzimavroudis $G$ et al. Closure of an iatrogenic rectal perforation with the endoloop/clips technique in a purse-string fashion. Ann Gastroenterol 2014; 27: 264

[5] Hookey LC, Khokhotva V, Bielawska B et al. The Queen's closure: a novel technique for closure of endoscopic gastrotomy for natural-orifice transluminal endoscopic surgery. Endoscopy 2009; 41: 149-153
Bibliography

Endoscopy 2021; 53: E433-E434

DOI $10.1055 / a-1333-0620$

ISSN 0013-726X

published online 27.1.2021

(c) 2021. Thieme. All rights reserved.

Georg Thieme Verlag KG, Rüdigerstraße 14,

70469 Stuttgart, Germany

\section{ENDOSCOPY E-VIDEOS \\ https://eref.thieme.de/e-videos}

$\square$ Endoscopy E-Videos is a free Feccess online section, reporting 回些: on interesting cases and new techniques in gastroenterological endoscopy. All papers include a high quality video and all contributions are freely accessible online.

This section has its own submission website at https://mc.manuscriptcentral.com/e-videos 